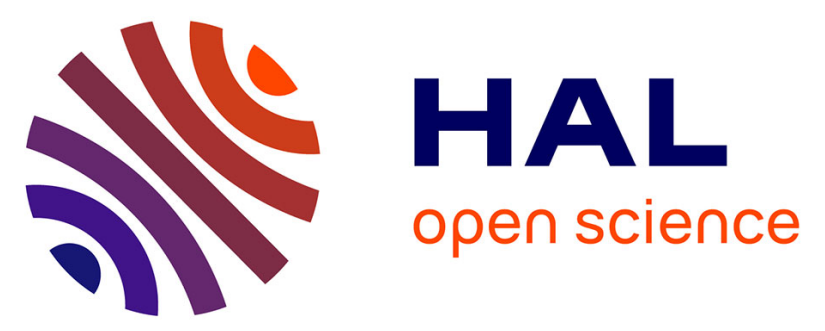

\title{
Twelve-year mortality in HIV-infected patients receiving antiretroviral therapy (ART): the role of social vulnerability. The ANRS CO8 APROCO-COPILOTE cohort
}

Camelia Protopopescu, François Raffi, Bruno Spire, Lucile Hardel, Christian Michelet, Christine Cheneau, Vincent Le Moing, Catherine Leport, Maria Patrizia Carrieri

\section{- To cite this version:}

Camelia Protopopescu, François Raffi, Bruno Spire, Lucile Hardel, Christian Michelet, et al.. Twelveyear mortality in HIV-infected patients receiving antiretroviral therapy (ART): the role of social vulnerability. The ANRS CO8 APROCO-COPILOTE cohort. Antiviral Therapy, 2015, 20 (7), pp.763-772. 10.3851/IMP2960 . hal-01299300

HAL Id: hal-01299300

https://hal-univ-rennes1.archives-ouvertes.fr/hal-01299300

Submitted on 14 Jun 2016

HAL is a multi-disciplinary open access archive for the deposit and dissemination of scientific research documents, whether they are published or not. The documents may come from teaching and research institutions in France or abroad, or from public or private research centers.
L'archive ouverte pluridisciplinaire HAL, est destinée au dépôt et à la diffusion de documents scientifiques de niveau recherche, publiés ou non, émanant des établissements d'enseignement et de recherche français ou étrangers, des laboratoires publics ou privés. 
Antiviral Therapy, 20, 763-772, doi: 10.3851/IMP2960

\title{
Original article
}

\section{Twelve-year mortality in HIV-infected patients receiving antiretroviral therapy (ART): the role of social vulnerability. The ANRS $C 08$ APROCO-COPILOTE cohort}

\author{
Camelia Protopopescu ${ }^{1,2,3 *}$, François Raffi ${ }^{4}$, Bruno Spire ${ }^{1,2,3}$, Lucile Hardel ${ }^{5}$, Christian Michelet $^{6}$, \\ Christine Cheneau ${ }^{7}$, Vincent Le Moing ${ }^{8}$, Catherine Leport ${ }^{9}, 10$, Maria Patrizia Carrieri ${ }^{1,2,3}$, the \\ ANRS CO8 APROCO-COPILOTE Study Group \\ ${ }^{1}$ INSERM, UMR912 (SESSTIM), 13006 Marseille, France \\ ${ }^{2}$ Aix Marseille Université, UMR_S912, IRD, 13006 Marseille, France \\ ${ }^{3}$ ORS PACA, Observatoire Régional de la Santé Provence-Alpes-Côte d'Azur, Marseille, France \\ ${ }^{4}$ CMIT, Paris, France \\ ${ }^{5}$ INSERM, U897, Université Bordeaux Segalen, ISPED, Bordeaux, France \\ ${ }^{6} \mathrm{CHU}$ de Rennes, Rennes, France \\ ${ }^{7}$ Hôpital Civil - CISIH, CHRU de Strasbourg, Strasbourg, France \\ ${ }^{8}$ Service des Maladies Infectieuses et Tropicales, CHU de Montpellier, UMI 233 TransVIHMI, \\ IRD, Université Montpellier 1, Montpellier, France \\ ${ }^{9}$ Université Paris Diderot, Paris, France \\ ${ }^{10}$ INSERM, IAME, UMR 1137, Paris, France \\ *Corresponding author e-mail: camelia.protopopescu@inserm.fr
}

\begin{abstract}
Background: Although the role of clinical/biological factors associated with mortality has already been explored in HIV-infected patients on ART, to date little attention has been given to the potential role of social vulnerability. This study aimed to construct an appropriate measure of social vulnerability and to evaluate whether this measure is predictive of increased mortality risk in ART-treated patients followed up in the ANRS CO8 APROCO-COPILOTE cohort.

Methods: The cohort enrolled 1,281 patients initiating a protease inhibitor-based regimen in 1997-1999. Clinical/laboratory data were collected every 4 months. Self-administered questionnaires collected psycho-social/behavioural characteristics at enrolment (M0), M4, and every 8-12 months thereafter. A Multiple Correspondence Analysis using education, employment and housing indicators helped construct a composite indicator measuring social vulnerability. The outcome studied was all-cause deaths occurring after M4. The relationship between social vulnerability and mortality, after adjustment for other predictors, was studied using a sharedfrailty Cox model, taking into account informative study dropout.

Results: Over a median [IQR] follow-up of 7.9 [3.0;11.2] years, 121 deaths occurred among 1,057 eligible patients, corresponding to a mortality rate of $[95 \% \mathrm{CI}]=1.64[1.37 ; 1.96] / 100$ personyears. Leading causes of death were non-AIDS defining cancers $(n=26)$, AIDS $(n=23)$, and cardiovascular diseases $(\mathrm{n}=12)$. Social vulnerability $(\mathrm{HR}[95 \% \mathrm{CI}]=1.2[1.0 ; 1.5])$ was associated with increased mortality risk, after adjustment for other known behavioural and bio-medical predictors.
\end{abstract}


Conclusions: Social vulnerability remains a major mortality predictor in ART-treated patients. A real need exists for innovative interventions targeting individuals cumulating several sources of social vulnerability, to ensure that social inequalities do not continue to lead to higher mortality.

\section{Running head: Mortality in HIV-infected patients on ART: the role of social vulnerability}

\section{Introduction}

Enough evidence exists today to show that HIV-related mortality has been greatly reduced since the introduction of potent antiretroviral therapy (ART) $(1,2)$. Indeed, HIV-infected patients who are not drug users or coinfected with hepatitis $\mathrm{C}$ virus (HCV) now tend to have mortality rates similar to those observed in the general population, at least in high-income North American and European countries (3-5). Known factors leading to higher HIV-related mortality include delayed HIV screening $(6,7)$, delayed care $(8-10)$, non-adherence to treatment $(11,12)$, exposure to certain antiretroviral agents (13), accelerated aging driven by residual immune activation (14), and finally, co-occurrence of other virus/diseases (e.g., hepatitis C) $(3,15)$. In addition, certain lifestyle factors such as smoking, alcohol consumption and drug use may also contribute to increase the risk of mortality (16-18).

Social vulnerability can be regarded more as a structural-level exposure, related to the risk environment framework, than as an individual factor (19). It can potentially interfere with patient response to ART, through reduced access to the different components of the optimal HIV care cascade (HIV screening, referral to HIV care, access to HIV treatment) (20-23).

Before the arrival of ART, results regarding the impact of socio-economic status on mortality of HIV-infected patients were heterogeneous, with some studies outlining no impact $(24,25)$, while others highlighted the opposite $(26,27)$. The impressive increase in survival rates thanks to ART has facilitated increased research into competing risk factors of mortality, including unhealthy behaviors (16-18) and low socio-economic status $(28,29)$. However, some heterogeneity still remains in post-ART studies, perhaps due to major differences in the United States' health system $(28,30)$ and those in Canada (29) or Western European (31-33) countries, or to the fact that different socio-economic indicators, measured at household or regional level, were used as predictors of mortality $(28,29,34)$. To date, several European studies focusing on HIV-positive individuals have found an association between mortality and either education level $(7,31,32)$ or income $(33)$, but few have tried to measure social vulnerability and instability in a more complete manner (35). Socio-economic status and education are important components of social vulnerability but they have been rarely combined to create a more complex indicator. Although educational level is already known to be a predictor of increased mortality in the general population $(36,37)$, few studies have explored the complexity of the relationship between educational level and other socio-economic indicators in HIV-infected patients. Furthermore, none has linked such a global indicator of social vulnerability to survival rates.

We used the 12-year French ANRS CO8 APROCO-COPILOTE cohort follow-up of HIV-infected individuals, started on ART in 1997-1999, to develop an original combined indicator of social vulnerability, based on different proxies of socioeconomic status measured at baseline, and to evaluate whether this indicator, is a significant predictor of mortality, independently of other clinical and behavioural predictors. In our study, we decided to exclude early mortality (i.e. deaths arising during the first 4 months after ART initiation), which are mainly due to pre-existing severe clinical and immunovirological statuses before ART initiation, as initial ART exposure could not have prevented this early mortality. 


\section{Methods}

Study design

The APROCO-COPILOTE cohort was designed to study the clinical, immunological, virological, and socio-behavioural course of HIV disease in HIV-1 infected individuals who started the first generation of combined antiretroviral regimens, which included protease inhibitors (PI). Between May 1997 and June 1999, patients $(n=1,281)$ were enrolled in the cohort in 47 centres throughout France, at their first ART prescription, and clinically followed up every 4 months thereafter until the end of the study (month 144, written M144).

\section{Data Collection}

At each follow-up visit, the supervising HIV physician completed a form that included the patient's clinical and laboratory data, including HIV CDC clinical stage defined by the Centers for Disease Control and Prevention (CDC) (38), plasma HIV RNA level, CD4 ${ }^{+}$cell count, hemoglobin concentration, aspartate and alanine transaminase (AST, ALT) levels, platelet count, serum creatinine level and weight.

The medical questionnaire at enrolment included additional data about the patient's HIV history: HIV transmission category (intravenous drug use (IDU), sex between men, or other), time since HIV diagnosis, exposure to antiretroviral treatment before enrolment in the cohort, time since ARV initiation, and coinfection with HCV at M0.

At M0, M4, and every 8 months thereafter during the first five years of follow-up, and then every 12 months thereafter, a self-administered questionnaire collected data on sociodemographic characteristics including age, gender, having a steady partner or not and indicators of social status such as education level, employment status, housing stability and housing comfort. These questionnaires also gathered information about patients' behaviours (adherence to ART, tobacco and alcohol consumption) and experience with the disease and its treatment (selfreported side effects, depressive symptoms).

\section{Participants}

For the present analysis we selected all patients who completed the self-administered questionnaire at enrolment (M0) and at least one other self-administered questionnaire or who died after the first 4 months of follow-up $(n=1,057)$. The study period targeted the follow-up period between M4 and M144, and only visits where a corresponding self-administered questionnaire was administered were included in the analysis.

\section{Variables}

The outcome used in this analysis was deaths (from all causes) occurring between M4 and M144 in the selected patients. The overall mortality rate was computed as the number of deaths occurring between M4 and M144 over the number of person-years during the study period. A composite continuous indicator of social vulnerability was created using a Multiple Correspondence Analysis (MCA), performed on the basis of the following socio-economic binary indicators measured at M0: having a high school certificate (yes/no), being employed (yes/no), having stable housing (yes/no), and having comfortable housing (yes/no). The composite continuous indicator was defined by the first of the two factors (with reversed sign) identified in the MCA solution.

The following eight clinical variables were tested in the multivariate analysis to adjust for potential predictors of mortality and confounding effects: AIDS stage; being antiretroviral naive 
at M0; time since HIV diagnosis; plasma HIV RNA>100,000 copies/mL at M0; poor early immune status (CD4 counts/mm $\mathrm{mm}^{3}<200$ at both M0 and M4); a validated indicator of advanced liver fibrosis (defined as FIB-4>3.25 (39), where FIB-4 is an index based on age, AST, ALT and platelet count $(39,40)$ ); anaemia (defined as a haemoglobin concentration $<12 \mathrm{~g} / \mathrm{dL}$ for women and $<13 \mathrm{~g} / \mathrm{dL}$ for men); a validated indicator of renal impairment based on estimated creatinine clearance (ECC), computed using the Cockcroft-Gault formula (with ECC $<60 \mathrm{~mL} / \mathrm{min}$ defining moderate/severe renal impairment) (41).

Furthermore, the following seven self-reported psychosocial and behavioural characteristics were measured and tested in the multivariate analysis: presence of depressive symptoms (using an indicator based on the validated French version of the Center for Epidemiologic Studies Depression Scale (CES-D) scale, and defined as a CES-D score > 17 in men and $>23$ in women) (42); tobacco smoking (using a binary indicator based on the average number of cigarettes smoked daily during the 4 previous weeks (smoking $>20$ cigarettes/day)); average daily alcohol consumption (43) (with the following categories: no consumption, low ( $\leq 1$ alcohol units (AU)/day), moderate (1-3 AU/day for women and 1-4 AU/day for men), and elevated (>3 AU/day for women and >4 AU/day for men)); regular binge drinking (i.e. drinking $\geq 5 \mathrm{AU}$ on one occasion, at least once a month); perceived side-effects (using a score based on a 13-item scale of self-reported symptoms and the discomfort they caused, in accordance with the French version of the symptom index developed by Justice et al (44), and described elsewhere (45); adherence to ART (using a three-level score (high, moderate and low adherence) based on a validated algorithm using the ART doses, both prescribed and those actually taken, during the previous 4 days (46), according to the methodology established by the AIDS Clinical Trial Group (47)).

Psychosocial characteristics (having a steady partner, depressive symptoms, tobacco and alcohol consumption, adherence to ART, and self-reported symptoms), as well as biological characteristics (anaemia, the indicator of liver fibrosis, and the indicator of renal impairment) were evaluated at each visit and used as time-varying covariates in the statistical analyses. In the case of a missing value for any time-varying covariate, the last available value before the current visit was carried forward. All other variables (see Table 2) were used as fixed covariates, measured at M0, M1 or M4, as we wished to assess the effect of pre-ART or early clinicalimmunovirological characteristics on mortality.

\section{Statistical methods}

The main characteristics at enrolment were compared between the 1,057 patients selected for this study and the 1,281 patients enrolled in the cohort, using Chi-2 tests and nonparametric Wilcoxon signed-ranks tests.

The follow-up period was defined for each patient as the period from M4 until his/her dropout from the cohort (i.e. the last follow-up visit with an available completed selfadministered questionnaire) or death. The association between the composite indicator of social vulnerability and mortality was assessed after adjustment for all potential predictors and confounding factors, using a shared-frailty Cox proportional hazards (PH) model. This model is an extension of the standard Cox PH model, able to take into account informative study dropout (48). In the shared-frailty Cox model the patients were grouped into clusters according to their dropout time, each cluster having a specific baseline hazard ratio (individuals in the same cluster shared the same baseline hazard ratio, so that their times of death were correlated). Further details about the shared-frailty Cox model are provided in the Appendix. The number of clusters was assessed by plotting the cumulative hazard function for death according to three categories 
defined by the patients' dropout time: before M20, between M20 and M60, and after M60 (see Figure 1). This allowed us to identify two main patterns, corresponding to two clusters defined by a dropout time before or after 60 months, respectively (individuals having their last available selfadministered questionnaire before M60 were more likely to die than the others, due to unobserved heterogeneity). As is the case with most self-reported health-related data, the dropout time was very likely to be informative, as the sickest patients were more likely to have missing data.

Potential adjustment variables having a liberal significance level of $\mathrm{P}<0.20$ (Wald test) in the univariate analyses were considered eligible for inclusion in the multivariate analysis. A backward selection procedure was then used to select adjustment variables in the final multivariate model (variables were considered significantly associated with the outcome if $\mathrm{P} \leq$ 0.05). A likelihood ratio (LR) test (see Appendix) was used to test the shared-frailty Cox PH specification versus the standard Cox $\mathrm{PH}$ specification in the final multivariate model. Plausible interactions were assessed by creating interaction terms and adding them to the main effects model to test for their significance.

Stata/SE 12.1 for Windows (49) software was used for all analyses.

\section{Results}

The main characteristics of the 1,057 patients selected for this study were not significantly different from those of the 1,281 patients enrolled in the cohort in terms of gender, age, and clinical characteristics at baseline (results not shown).

The 1,057 patients selected for this analysis had a median (IQR) total follow-up period of 7.9 (3.0;11.2) years, representing 7,379 person-years (counting from 4 months of follow-up onwards). The dropout time (i.e. the maximum follow-up time corresponding to a completed selfadministered questionnaire) was before M20, between M20-M60 and after M60 for, respectively, $20 \%, 22 \%$ and $58 \%$ of the selected patients.

A total of 147 deaths occurred in the cohort, among which 17 patients had not a completed self-administered questionnaire at M0 and 9 deaths occurred during the first 4 months of follow-up. The other 121 deaths, occurring between M4 and M144 among the 1,057 selected patients, were included in this study, corresponding to an overall mortality rate [95\% confidence interval (CI)] of 1.64 [1.37;1.96] per 100 person-years from 4 months after ART initiation onwards.

The main causes of death were non-AIDS defining cancers $(n=26)$, AIDS $(n=23)$ and cardiovascular diseases $(n=12)$. The causes of death are described in detail in Table 1. The selected patients were mostly males $(78 \%)$ and their median age at enrolment was 36 years [interquartile range (IQR), 32;42]. Of the 1,057, 41\% were infected through sex between men, and $17 \%$ through IDU. A quarter (25\%) was born outside of Europe. At M4, 58\%, 18\%, 4\% and $20 \%$ reported, respectively, low, moderate, elevated, and no alcohol consumption. Nineteen percent smoked more than 20 cigarettes/day and a third of patients reported depressive symptoms.

With respect to the four binary socio-economic indicators used in the MCA, the prevalence of 'No' answers was $65 \%, 41 \%, 20 \%$, and $14 \%$ for, respectively, having a high school certificate, being employed, housing stability and housing comfort at M0 (see Table 2). The solution with two dimensions was retained in the MCA, explaining $58 \%$ of the total variance (35.6\% and $22.5 \%$ for the first and second dimensions, respectively). Eigenvalues were 1.4 and 0.9 for the first and second dimensions, respectively. The first dimension distinguished 'Yes' and 'No' categories, with all 'No' categories located close to the negative side of the first axis and all 
'Yes' categories located close to its positive side. Accordingly, the first factor of the MCA can be interpreted as a measure of good 'general' socio-economic status. We defined an indicator measuring 'social vulnerability' given by the reversed sign of the first factor, so that higher values of the indicator correspond to higher levels of social vulnerability. This composite indicator of social vulnerability varied between -2.60 and 1.33 , with a median [IQR] of -0.35 [$0.47 ; 0.51]$. The employment item provided the highest contribution to this social vulnerability indicator (the corresponding discrimination measures for employment status, housing stability, education level and housing comfort were $0.48,0.34,0.34$ and 0.27 , respectively).

With regard to clinical characteristics, $44 \%$ of the selected patients were treatment naive, a quarter $(25 \%)$ had been diagnosed more than 8 years before enrolment in the cohort (i.e. before the initiation of a PI-containing therapy), $20 \%$ had already experienced progression to AIDS before enrolment, $37.6 \%$ had a CD4 cell count below 200 cells $/ \mathrm{mm}^{3}, 30.1 \%$ had a plasma HIV RNA level greater than 100,000 copies/mL and approximately $22 \%$ were $\mathrm{HCV}$-coinfected at M0. Table 2 shows factors potentially associated with mortality (univariate and multivariate analyses). Among the socio-behavioural factors, social vulnerability (as measured by the composite indicator), the presence of depressive symptoms and the number of self-reported symptoms causing discomfort were all associated with a higher risk of death.

With respect to clinical correlates eligible for the multivariate model, patients infected through sex between men were at lower risk of mortality. Conversely, patients with the following characteristics had a significantly higher risk of mortality: HCV coinfection, AIDS at M0 (i.e. progression to AIDS before ART initiation), longer delays between HIV diagnosis and ART initiation, plasma HIV RNA values over 100,000 copies/mL at enrolment, no increase over 200 CD4 cell count after initial 4 months of treatment, time-varying anaemia and indication of advanced liver fibrosis.

In our study, no significant association (no main effect and no confounding effect) was found in univariate analyses between mortality risk and the following known correlates and confounders: gender, time since ARV initiation at M0, renal impairment, having a steady partner, regular binge drinking, smoking > 20 cigarettes/day, and adherence to ART.

In the multivariate analysis (Table 2), higher levels of social vulnerability (HR [95\% $\mathrm{CI}]=1.2[1.0 ; 1.5])$ were independently associated with higher mortality risk, after adjustment for other significant known correlates as follows: age, AIDS stage at M0, plasma HIV RNA>100,000 copies/mL at enrolment (HR $[95 \% \mathrm{CI}]=1.7[1.0 ; 2.9])$, poor early immune status (CD4 counts $/ \mathrm{mm}^{3}<200$ at both M0 and M4) $(\mathrm{HR}[95 \% \mathrm{CI}]=2.3[1.3 ; 4.1])$, being antiretroviral naive and time since HIV diagnosis, anaemia (HR [95\% CI] $=2.4$ [1.5;3.7]), advanced liver fibrosis during follow-up $(\mathrm{HR}[95 \% \mathrm{CI}]=2.5[1.5 ; 4.3])$ and low alcohol consumption $(\leq 1 \mathrm{AU} /$ day, versus no consumption) (HR $[95 \% \mathrm{CI}]=0.6[0.4 ; 1.0])$. With regard to the interaction effects, a significant relationship between being antiretroviral naive and increased mortality risk was found only among patients who had been diagnosed more than 8 years before enrolment in the cohort $(\mathrm{HR}[95 \% \mathrm{CI}]=2.8[1.4 ; 5.4])$. Accordingly, time since diagnosis was an effect modifier for being antiretroviral naive at enrolment. Furthermore, the clinical CDC stage at enrolment was an effect modifier for age as the association between age and increased mortality risk was significant among the patients in stage A or B (HR $[95 \% \mathrm{CI}]=1.3[1.1 ; 1.7])$, but not significant among the patients in stage $\mathrm{C}$ at enrolment.

The results of the LR test $\left(\mathrm{P}<10^{-3}\right)$ seemed to favour the shared-frailty Cox PH model over the standard Cox PH model, as they provided strong evidence for the existence of significant latent patient frailty. 


\section{Discussion}

This is the first study to explore the effect of social vulnerability on mortality in a French national cohort of HIV-infected patients receiving ART. It shows that mortality risk increases by $20 \%$ per each unit increase of the social vulnerability index, even when taking other known clinical and behavioural predictors of mortality into account.

This study also shows that non-AIDS related cancers are the first cause of mortality today, while AIDS-related causes of death (including AIDS-defining cancers) constitute the second cause. The burden of co-infection is apparent, as in this cohort - which is representative of individuals exposed not only to the first generation of combined ART (i.e., PI-containing regimens) but also to suboptimal HBV and HCV care - the third most common cause of death was related to HCV or HBV associated complications. As a number of unknown causes of death were present in the study, we preferred to focus on overall mortality without any distinction of the cause.

To date, only one study, conducted in the US in the ART era, has shown that HIVinfected participants meeting the US government's definition of poverty were more likely to die than others. Specifically, it found they were 1.5 times more likely to die (30).

As our model is adjusted for longer periods since HIV diagnosis, for poor early immune status during the first four months of ART and for HIV plasma viral load before starting ART, we can presume that the most socially vulnerable patients were also those more likely to have encountered difficulties with adherence and to have experienced complications of immunosuppression or undiagnosed/untreated co-morbidities over the long term course of ART treatment.

The association between social vulnerability and mortality is even more striking in a country like France where access to care is free for anyone (all residents in France are covered by health insurance by law; most qualify for state health insurance, which generally reimburses $70 \%$ of patients' costs). This association reflects the fact that socially vulnerable individuals have to first cope with financial worries before thinking about their health status. It is worth noting that such populations tend to use emergency services more than the rest of the HIV-infected population (50), this greater utilization being an indicator of missed opportunities for early detection of severe comorbidities (given that non-AIDS related cancers are the first cause of death) or risk factors for acute fatal events (cardiovascular events were the third most common cause of death in this cohort).

Moreover, social vulnerability is often associated with psychiatric disorders, such as depressive symptoms, which were a major predictor of clinical progression in a previous analysis on the same cohort (51). It may also be correlated with addictive behaviours which may increase the risk of acute non-HIV related mortality (i.e. overdoses, suicides, road accidents, etc.) $(52,53)$.

Our results are consistent with other studies which showed that low socio-economic status and education are associated with increased mortality in HIV-infected individuals before and during the era of potent antiretroviral therapy $(16-18,26-29)$ and remain valid after adjustment for known significant correlates of mortality, as anaemia (56-58) or the indicator of liver fibrosis. This confirms recent trends indicating a decrease of HIV-related mortality, but also an increase in competing mortality causes related to liver-associated damage or comorbidities $(3,15)$. One Danish study (59) recently tried to disentangle the effects of (i) pre-treatment factors, in particular HIV-related risk factors (AIDS-defining diseases and insufficient response to ART), (ii) comorbidities including hepatitis $\mathrm{C}$, and (iii) behaviours (drug and excessive alcohol use), on overall mortality. It concluded that in HIV patients with no risk factors, the probability of survival was equivalent to that of the general population while the main burden of mortality was 
attributable to behaviours. However, that study did not take into account the changing pattern of predictors over time and factors like social vulnerability.

AIDS clinical stage at ART initiation remained a major predictor of mortality. The effect of clinical stage was so strong that it cancelled out the effect of age, the latter remaining significant only in patients who had not experienced progression to AIDS at enrolment. This result may be due to the specificity of the enrolled patients in the cohort.

Finally, we found an association between very low alcohol consumption and reduced mortality risk, which is in line with previous results for the same cohort (62), which showed that individuals with low alcohol consumption presented higher CD4 cell-counts. We do not know whether this association is more a proxy of general healthy habits or just "a French paradox", and further investigation in other cohorts is needed to verify this result. It is worth noting that some of the most important mortality risk factors, like elevated tobacco or alcohol use, were not associated with mortality risk in this study. This was perhaps due to the fact that lifetime cumulative exposure to alcohol or tobacco could not be computed, as this was not the original objective of the study. We did not find any effect of behavioural changes in elevated alcohol or tobacco use during follow-up (data not shown), perhaps because cumulative exposures may counterbalance certain possible positive effects of abstinence.

Our choice to use a shared-frailty Cox PH model specification, able to take into account informative study dropout, was justified by the results of the LR test for the existence of latent frailty depending on the cluster (dropout time before or after M60). Accordingly, the usual interpretation of effects based on the standard Cox PH model specification would not have been appropriate.

Some limitations of the study need to be mentioned. First, our results concern a HIVinfected population which is not representative of the population initiating ART today. This is because a non-negligible proportion of our study population (non-treatment naive patients) had been exposed to sub-optimal treatments before ART initiation, which is no longer the case for those starting treatment today. This may have resulted in increased mortality rates, although being antiretroviral naive was not significantly associated with mortality.

Furthermore, our study shows that even in the French national context of free access to care, social vulnerability still plays a role in the inequality of ART care. Although it is difficult to generalize our results to other countries, the impact of social vulnerability may be even stronger in countries where access to HIV care is not free for everyone.

While the use of a fixed baseline measure of social vulnerability may seem to be another limitation of the study, in reality it is not for two reasons. First, we recomputed the composite indicator at different specific follow-up times but it did not greatly evolve over time (data not shown). Second, we aimed to emphasize the importance for HIV clinicians to timely identify patients who, by combining several different sources of vulnerability due to their social conditions, require more comprehensive care, more frequent follow-up visits and ad hoc social interventions in order to obtain better response to ART.

To conclude, this study underlines the fact that social vulnerability is a major risk factor of mortality. Free access to HIV care is not enough to make HIV a chronic condition and ensure active ageing of people living with the disease. A real need exists for innovative social interventions targeting individuals cumulating several sources of social vulnerability, in order to protect their right to health care and to ensure that social inequalities do not continue to be a source of higher mortality among them.

\section{Acknowledgment statement}


The authors would like to thank all participating patients, nurses and physicians in clinical sites. We would also like to thank Jude Sweeney for the English revision and editing of the manuscript.

Funding sources: The ANRS CO8 (APROCO/COPILOTE) cohort is funded by ANRS (Agence Nationale de Recherches sur le Sida et les hépatites virales) and CMIT (Collège des Universitaires de Maladies Infectieuses et Tropicales), which received research grants from Abbott, Boehringer-Ingelheim, Bristol-Myers Squibb, GlaxoSmithKline, Gilead Sciences, Pfizer and Roche.

The funders were responsible for initiating, managing and financing the cohort, but did not interfere with data analysis and interpretation and dissemination of the scientific results.

Authors' contribution:

Camelia Protopopescu analyzed the data and wrote the manuscript; François Raffi was responsible for cohort initiation, contributed to patients' recruitment and investigation and revised the manuscript; Bruno Spire contributed to data analyses and revised the manuscript; Lucile Hardel contributed to patients' evaluation; Christian Michelet contributed to patients' recruitment and investigation; Christine Cheneau contributed to patients' recruitment and investigation; Vincent Le Moing contributed to patients' recruitment and investigation and revised the manuscript; Catherine Leport was responsible for cohort initiation, contributed to patients' recruitment and investigation and revised the manuscript; Maria Patrizia Carrieri planned the data analyses and wrote the manuscript. All authors approved the final version of the manuscript.

Previous presentations: Preliminary results have been presented in a poster at the 7th IAS Conference on HIV Pathogenesis, Treatment and Prevention (30th June-3th July 2013, Kuala Lumpur, Malaysia), the 14th European AIDS Conference (16th-19th October 2013, Brussels, Belgium), and the 18th International Workshop on HIV Observational Databases (27th-29th March 2014, Sitges, Spain).

Disclosure statement: All authors have no conflicts of interest to declare.

\section{The ANRS CO8 APROCO-COPILOTE Study Group is composed of the following:} Scientific Committee:

- Steering Committee:

Principal investigators: C. Leport, F. Raffi

Methodology: G. Chêne, R. Salamon

Social sciences: JP. Moatti, J. Pierret, B. Spire

Virology: F. Brun-Vézinet, H. Fleury, B. Masquelier

Pharmacology: G. Peytavin, R. Garraffo

- Other members: D. Costagliola, P. Dellamonica, C. Katlama, L. Meyer, D. Salmon, A. Sobel. Events Validation Committee: L. Cuzin, M. Dupon, X. Duval, V. Le Moing, B. Marchou, T. May, P. Morlat, C. Rabaud, A. Waldner-Combernoux.

Project coordination: P. Reboud.

ANRS representatives: Sandrine Couffin-Cadiergues, Lucie Marchand.

Data monitoring and statistical analysis: V. Bouteloup, AD. Bouhnik, C. Brunet-François, V. Caron, MP. Carrieri, M. Courcoul, F. Couturier, L. Hardel, L. Iordache. P. Kurkdji, S. Martiren, M. Préau, C. Protopopescu, J. Surzyn, A.Taieb, V. Villes. 
Promotion: Agence Nationale de Recherches sur le Sida et les hépatites virales (ANRS, Action Coordonnée $\mathrm{n}^{\circ}$ 7).

Other support: Collège des Universitaires de Maladies Infectieuses et Tropicales (CMIT ex APPIT), Sidaction Ensemble contre le Sida and associated pharmaceutical companies: Abbott, Boehringer-Ingelheim, Bristol-Myers Squibb, GlaxoSmithKline, Gilead Sciences, Pfizer and Roche.

Clinical Centres (investigators): Amiens (Pr JL. Schmit), Angers (Dr JM. Chennebault), Belfort (Dr JP. Faller), Besançon (Pr N. Mgy-Bertrand, Pr B. Hoen, Dr Drobachef), Bobigny (Pr O. Bouchaud), Bordeaux (Pr M. Dupon, Pr Longy-Boursier, Pr P. Morlat, Pr JM. Ragnaud), Bourgen-Bresse (Dr P. Granier), Brest (Pr M. Garré), Caen (Pr R. Verdon), Compiègne (Dr D. Merrien), Corbeil Essonnes (Dr A. Devidas), Créteil (Pr A. Sobel), Dijon (Pr L. Piroth), Garches (Pr C. Perronne), Lagny (Dr E. Froguel), Libourne (Dr J. Ceccaldi), Lyon (Pr D. Peyramond), Meaux (Dr C. Allard), Montpellier (Pr J. Reynes), Nancy (Pr T. May), Nantes (Pr F. Raffi), Nice (Pr JG Fuzibet, Pr P. Dellamonica), Orléans (Dr P. Arsac), Paris (Pr E. Bouvet, Pr F. Bricaire, Pr P. Bergmann, Pr J. Cabane, Dr J. Monsonego, Pr PM. Girard, Pr L. Guillevin, Pr S. Herson, Pr C.Leport, Pr MC. Meyohas, Pr JM. Molina, Pr G. Pialoux, Pr D. Salmon), Poitiers (Pr P. Roblot), Reims (Pr R. Jaussaud), Rennes (Pr C. Michelet), Saint-Etienne (Pr F. Lucht), Saint-Mandé (Pr T. Debord), Strasbourg (Dr D. Rey), Toulon (Dr JP. De Jaureguiberry), Toulouse (Pr B. Marchou), Tours (Pr L. Bernard).

\section{References}

1. Mocroft A, Ledergerber B, Katlama C, Kirk O, Reiss P, d'Arminio Monforte A, et al. Decline in the AIDS and death rates in the EuroSIDA study: an observational study. Lancet. 2003;362(9377):22-9.

2. Palella FJ, Jr., Baker RK, Moorman AC, Chmiel JS, Wood KC, Brooks JT, et al. Mortality in the highly active antiretroviral therapy era: changing causes of death and disease in the HIV outpatient study. J Acquir Immune Defic Syndr. 2006;43(1):27-34.

3. Hernando V, Perez-Cachafeiro S, Lewden C, Gonzalez J, Segura F, Oteo JA, et al. All-cause and liver-related mortality in HIV positive subjects compared to the general population: differences by $\mathrm{HCV}$ co-infection. J Hepatol. 2012;57(4):743-51.

4. Lewden C, Bouteloup V, De Wit S, Sabin C, Mocroft A, Wasmuth JC, et al. All-cause mortality in treated HIV-infected adults with CD $4>/=500 / \mathrm{mm} 3$ compared with the general population: evidence from a large European observational cohort collaboration. Int J Epidemiol. 2012;41(2):433-45.

5. Antiretroviral Therapy Cohort C, Zwahlen M, Harris R, May M, Hogg R, Costagliola D, et al. Mortality of HIV-infected patients starting potent antiretroviral therapy: comparison with the general population in nine industrialized countries. Int J Epidemiol. 2009;38(6):1624-33.

6. Sobrino-Vegas P, Garcia-San Miguel L, Caro-Murillo AM, Miro JM, Viciana P, Tural C, et al. Delayed diagnosis of HIV infection in a multicenter cohort: prevalence, risk factors, response to HAART and impact on mortality. Current HIV research. 2009;7(2):224-30.

7. Sobrino-Vegas P, Rodriguez-Urrego J, Berenguer J, Caro-Murillo AM, Blanco JR, Viciana P, et al. Educational gradient in HIV diagnosis delay, mortality, antiretroviral treatment initiation and response in a country with universal health care. Antivir Ther. 2012;17(1):1-8.

8. Battegay M, Fehr J, Fluckiger U, Elzi L. Antiretroviral therapy of late presenters with advanced HIV disease. The Journal of antimicrobial chemotherapy. 2008;62(1):41-4.

9. Antinori A, Coenen T, Costagiola D, Dedes N, Ellefson M, Gatell J, et al. Late presentation of HIV infection: a consensus definition. HIV medicine. 2011;12(1):61-4.

10. Mocroft A, Lundgren JD, Sabin ML, Monforte A, Brockmeyer N, Casabona J, et al. Risk factors and outcomes for late presentation for HIV-positive persons in Europe: results from the Collaboration of Observational HIV Epidemiological Research Europe Study (COHERE). PLoS Med.

2013;10(9):e1001510. 
11. Garcia de Olalla P, Knobel H, Carmona A, Guelar A, Lopez-Colomes JL, Cayla JA. Impact of adherence and highly active antiretroviral therapy on survival in HIV-infected patients. J Acquir Immune Defic Syndr. 2002;30(1):105-10.

12. Lima VD, Geller J, Bangsberg DR, Patterson TL, Daniel M, Kerr T, et al. The effect of adherence on the association between depressive symptoms and mortality among HIV-infected individuals first initiating HAART. AIDS. 2007;21(9):1175-83.

13. Palella FJ, Jr., Armon C, Buchacz K, Chmiel JS, Novak RM, D'Aquila RT, et al. Factors associated with mortality among persistently viraemic triple-antiretroviral-class-experienced patients receiving antiretroviral therapy in the HIV Outpatient Study (HOPS). The Journal of antimicrobial chemotherapy. 2014;69(10):2826-34.

14. Taiwo B, Barcena L, Tressler R. Understanding and controlling chronic immune activation in the HIV-infected patients suppressed on combination antiretroviral therapy. Curr HIV/AIDS Rep.

2013;10(1):21-32.

15. Fuster D, Cheng DM, Quinn EK, Nunes D, Saitz R, Samet JH, et al. Chronic hepatitis C virus infection is associated with all-cause and liver-related mortality in a cohort of HIV-infected patients with alcohol problems. Addiction. 2014;109(1):62-70.

16. DeLorenze GN, Weisner C, Tsai AL, Satre DD, Quesenberry CP, Jr. Excess mortality among HIV-infected patients diagnosed with substance use dependence or abuse receiving care in a fully integrated medical care program. Alcohol Clin Exp Res.35(2):203-10.

17. Walley AY, Cheng DM, Libman H, Nunes D, Horsburgh CR, Jr., Saitz R, et al. Recent drug use, homelessness and increased short-term mortality in HIV-infected persons with alcohol problems. Aids. 2008;22(3):415-20.

18. Benard A, Bonnet F, Tessier JF, Fossoux H, Dupon M, Mercie P, et al. Tobacco addiction and HIV infection: toward the implementation of cessation programs. ANRS CO3 Aquitaine Cohort. AIDS Patient Care STDS. 2007;21(7):458-68.

19. Milloy MJ, Marshall BD, Kerr T, Buxton J, Rhodes T, Montaner J, et al. Social and structural factors associated with HIV disease progression among illicit drug users: a systematic review. Aids. 2012;26(9):1049-63.

20. Uphold CR, Mkanta WN. Review: use of health care services among persons living with HIV infection: state of the science and future directions. AIDS Patient Care STDS. 2005;19(8):473-85.

21. Vanlandingham M, Im-Em W, Yokota F. Access to treatment and care associated with HIV infection among members of AIDS support groups in Thailand. AIDS Care. 2006;18(7):637-46.

22. Joy R, Druyts EF, Brandson EK, Lima VD, Rustad CA, Zhang W, et al. Impact of neighborhoodlevel socioeconomic status on HIV disease progression in a universal health care setting. J Acquir Immune Defic Syndr. 2008;47(4):500-5.

23. Nearns J, Baldwin JA, Clayton H. Social, behavioral, and health care factors associated with recent HIV testing among sexually active non-Hispanic Black Women in the United States. Womens Health Issues. 2009;19(1):52-60.

24. Chaisson RE, Keruly JC, Moore RD. Race, sex, drug use, and progression of human immunodeficiency virus disease. N Engl J Med. 1995;333(12):751-6.

25. Katz MH, Hsu L, Lingo M, Woelffer G, Schwarcz SK. Impact of socioeconomic status on survival with AIDS. Am J Epidemiol. 1998;148(3):282-91.

26. Hogg RS, Strathdee SA, Craib KJ, O'Shaughnessy MV, Montaner JS, Schechter MT. Lower socioeconomic status and shorter survival following HIV infection. Lancet. 1994;344(8930):1120-4.

27. Schechter MT, Hogg RS, Aylward B, Craib KJ, Le TN, Montaner JS. Higher socioeconomic status is associated with slower progression of HIV infection independent of access to health care. J Clin Epidemiol. 1994;47(1):59-67.

28. McFarland W, Chen S, Hsu L, Schwarcz S, Katz M. Low socioeconomic status is associated with a higher rate of death in the era of highly active antiretroviral therapy, San Francisco. J Acquir Immune Defic Syndr. 2003;33(1):96-103. 
29. Wood E, Montaner JS, Chan K, Tyndall MW, Schechter MT, Bangsberg D, et al. Socioeconomic status, access to triple therapy, and survival from HIV-disease since 1996. Aids. 2002;16(15):2065-72.

30. McMahon J, Wanke C, Terrin N, Skinner S, Knox T. Poverty, hunger, education, and residential status impact survival in HIV. AIDS Behav. 2011;15(7):1503-11.

31. Legarth R, Omland LH, Kronborg G, Larsen CS, Pedersen C, Gerstoft J, et al. Educational attainment and risk of HIV infection, response to antiretroviral treatment, and mortality in HIV-infected patients. AIDS. 2014;28(3):387-96.

32. Lewden C, Raffi F, Cuzin L, Cailleton V, Vilde JL, Chene G, et al. Factors associated with mortality in human immunodeficiency virus type 1-infected adults initiating protease inhibitor-containing therapy: role of education level and of early transaminase level elevation (APROCO-ANRS EP11 study). The Antiproteases Cohorte Agence Nationale de Recherches sur le SIDA EP 11 study. J Infect Dis. 2002;186(5):710-4.

33. Piketty C, Castiel P, Giral P, Lhomme JP, Boubilley D, Olievenstein C, et al. Lack of legal income is strongly associated with an increased risk of AIDS and death in HIV-infected injecting drug users. AIDS Care. 1999;11(4):429-36.

34. McDavid Harrison K, Ling Q, Song R, Hall HI. County-level socioeconomic status and survival after HIV diagnosis, United States. Ann Epidemiol. 2008;18(12):919-27.

35. Bouhnik AD, Chesney M, Carrieri P, Gallais H, Moreau J, Moatti JP, et al. Nonadherence among HIV-infected injecting drug users: the impact of social instability. J Acquir Immune Defic Syndr. 2002;31 Suppl 3:S149-53.

36. Huisman M, Kunst AE, Bopp M, Borgan JK, Borrell C, Costa G, et al. Educational inequalities in cause-specific mortality in middle-aged and older men and women in eight western European populations. Lancet. 2005;365(9458):493-500.

37. Stirbu I, Kunst AE, Bopp M, Leinsalu M, Regidor E, Esnaola S, et al. Educational inequalities in avoidable mortality in Europe. J Epidemiol Community Health. 2010;64(10):913-20.

38. CDC. 1993 revised classification system for HIV infection and expanded surveillance case definition for AIDS among adolescents and adults. MMWR Recomm Rep. 1992 Dec 18;41(RR-17):1-19. 39. Sterling RK, Lissen E, Clumeck N, Sola R, Correa MC, Montaner J, et al. Development of a simple noninvasive index to predict significant fibrosis in patients with HIV/HCV coinfection. Hepatology. 2006;43(6):1317-25.

40. Tate JP, Justice AC, Hughes MD, Bonnet F, Reiss P, Mocroft A, et al. An internationally generalizable risk index for mortality after one year of antiretroviral therapy. Aids. 2013;27(4):563-72.

41. Stevens LA, Coresh J, Greene T, Levey AS. Assessing kidney function--measured and estimated glomerular filtration rate. N Engl J Med. 2006;354(23):2473-83.

42. Radloff L. The CES-D scale: a self-report depression scale for research in the general population. Applied Psychology Measurement. 1977;3:385-491.

43. Bissell D, Paton A, Ritson B. ABC of alcohol. Help: referral. Br Med J (Clin Res Ed). 1982;284(6314):495-7.

44. Justice AC, Holmes W, Gifford AL, Rabeneck L, Zackin R, Sinclair G, et al. Development and validation of a self-completed HIV symptom index. J Clin Epidemiol. 2001;54 Suppl 1:S77-90.

45. Carrieri MP, Villes V, Raffi F, Protopopescu C, Preau M, Salmon D, et al. Self-reported sideeffects of anti-retroviral treatment among IDUs: a 7-year longitudinal study (APROCO-COPILOTE COHORT ANRS CO-8). Int J Drug Policy. 2007;18(4):288-95.

46. Protopopescu C, Raffi F, Roux P, Reynes J, Dellamonica P, Spire B, et al. Factors associated with non-adherence to long-term highly active antiretroviral therapy: a 10 year follow-up analysis with correction for the bias induced by missing data. The Journal of antimicrobial chemotherapy. 2009;64(3):599-606.

47. Chesney MA, Ickovics JR, Chambers DB, Gifford AL, Neidig J, Zwickl B, et al. Self-reported adherence to antiretroviral medications among participants in HIV clinical trials: the AACTG adherence instruments. Patient Care Committee \& Adherence Working Group of the Outcomes Committee of the Adult AIDS Clinical Trials Group (AACTG). AIDS Care. 2000;12(3):255-66. 
48. Therneau TM, Grambsch PM. Modeling Survival Data: Extending the Cox Model Springer; 2000.

49. StataCorp. Stata Statistical Software: Release 12. . In: College Station TSL, editor. 2011.

50. Arno PS, Bonuck KA, Green J, Fleishman J, Bennett CL, Fahs MC, et al. The impact of housing status on health care utilization among persons with HIV disease. J Health Care Poor Underserved. 1996;7(1):36-49.

51. Villes V, Spire B, Lewden C, Perronne C, Besnier JM, Garre M, et al. The effect of depressive symptoms at ART initiation on HIV clinical progression and mortality: implications in clinical practice. Antivir Ther. 2007;12(7):1067-74.

52. Cook JA, Burke-Miller JK, Cohen MH, Cook RL, Vlahov D, Wilson TE, et al. Crack cocaine, disease progression, and mortality in a multicenter cohort of HIV-1 positive women. Aids. 2008;22(11):1355-63.

53. Green TC, McGowan SK, Yokell MA, Pouget ER, Rich JD. HIV infection and risk of overdose: a systematic review and meta-analysis. Aids. 2012;26(4):403-17.

54. Engsig FN, Zangerle R, Katsarou O, Dabis F, Reiss P, Gill J, et al. Long-term Mortality in HIVPositive Individuals Virally Suppressed for $>3$ Years With Incomplete CD4 Recovery. Clin Infect Dis. 2014;58(9):1312-21.

55. Young J, Psichogiou M, Meyer L, Ayayi S, Grabar S, Raffi F, et al. CD4 cell count and the risk of AIDS or death in HIV-Infected adults on combination antiretroviral therapy with a suppressed viral load: a longitudinal cohort study from COHERE. PLoS Med.9(3):e1001194.

56. Gupta A, Nadkarni G, Yang WT, Chandrasekhar A, Gupte N, Bisson GP, et al. Early mortality in adults initiating antiretroviral therapy (ART) in low- and middle-income countries (LMIC): a systematic review and meta-analysis. PLoS One. 2011;6(12):e28691.

57. Hoffmann CJ, Fielding KL, Johnston V, Charalambous S, Innes C, Moore RD, et al. Changing predictors of mortality over time from cART start: implications for care. J Acquir Immune Defic Syndr. 2011;58(3):269-76.

58. Sullivan P. Associations of anemia, treatments for anemia, and survival in patients with human immunodeficiency virus infection. J Infect Dis. 2002;185 Suppl 2:S138-42.

59. Obel N, Omland LH, Kronborg G, Larsen CS, Pedersen C, Pedersen G, et al. Impact of non-HIV and HIV risk factors on survival in HIV-infected patients on HAART: a population-based nationwide cohort study. PLoS One. 2011;6(7):e22698.

60. Melekhin VV, Shepherd BE, Stinnette SE, Rebeiro PF, Turner MM, Sterling TR. Hemoglobin may contribute to sex differences in mortality among HIV-infected persons in care. PLoS One.7(9):e44999.

61. Marti-Carvajal AJ, Sola I, Pena-Marti GE, Comunian-Carrasco G. Treatment for anemia in people with AIDS. Cochrane Database Syst Rev. 2011(10):CD004776.

62. Carrieri MP, Protopopescu C, Raffi F, March L, Reboud P, Spire B, et al. Low alcohol consumption as a predictor of higher CD4+ cell count in HIV-treated patients: a french paradox or a proxy of healthy behaviors? The ANRS APROCO-COPILOTE CO-08 cohort. J Acquir Immune Defic Syndr. 2013;65(4):e148-50. 
Table 1. Causes of deaths, the ANRS CO8 APROCO-COPILOTE cohort (M4-M144)

\begin{tabular}{|ll|}
\hline Causes of deaths & $\mathbf{n}(\boldsymbol{\%})$ \\
\hline Non AIDS-related cancer & $26(21.5)$ \\
Undis-related & $23(19)$ \\
Cardiovascular diseases & $12(9.9)$ \\
Accident/aggression & $12(9.9)$ \\
HCV or HBV & $11(9.1)$ \\
Other infectious and parasitic diseases & $10(8.3)$ \\
Overdose & $7(5.8)$ \\
Suicide & $5(4.1)$ \\
Digestive diseases & $5(4.1)$ \\
Unexplained sudden death & $4(3.3)$ \\
Benign tumours & $3(2.5)$ \\
Respiratory diseases & $1(0.8)$ \\
Endocrine, nutritional and metabolic diseases & $1(0.8)$ \\
Total & $1(0.8)$ \\
\hline
\end{tabular}


Table 2. Characteristics of the study population and factors associated with deaths (sharedfrailty Cox proportional hazards model, univariate and multivariate analyses, the ANRS CO8 APROCO-COPILOTE cohort, M4-M144)

\begin{tabular}{|c|c|c|c|c|c|}
\hline & \multirow{2}{*}{$\begin{array}{c}\mathrm{N}(\%) \text { or } \\
\text { median } \\
{[I Q R] \text { at }} \\
\text { time origin }\end{array}$} & \multicolumn{2}{|c|}{ Univariate analyses } & \multicolumn{2}{|c|}{ Multivariate analysis } \\
\hline & & $\begin{array}{c}\text { HR } \\
{[95 \% \mathrm{CI}]}\end{array}$ & $\begin{array}{c}\text { P- } \\
\text { value }\end{array}$ & $\begin{array}{c}\text { AHR } \\
{[95 \% \mathrm{CI}]}\end{array}$ & $\begin{array}{c}\text { P- } \\
\text { value }\end{array}$ \\
\hline \multicolumn{6}{|l|}{ Clinical CDC stage at M0 \& Age } \\
\hline Clinical CDC stage $\mathrm{C}$ at $\mathrm{M} 0$ & $215(20.3)$ & $9.0[1.4 ; 57.7]$ & 0.021 & $6.2[0.8 ; 48.7]$ & 0.082 \\
\hline Age for patients in stage $\mathrm{C}$ at $\mathrm{M} 0$ & $38[34 ; 45]$ & $0.7[0.4 ; 1.0]$ & 0.050 & $0.9[0.6 ; 1.4]$ & 0.614 \\
\hline Age for patients in stage A-B at M0 & $36[32 ; 42]$ & $1.0[0.8 ; 1.2]$ & 0.973 & $1.3[1.1 ; 1.7]$ & 0.010 \\
\hline \multicolumn{6}{|l|}{$\begin{array}{l}\text { Antiretroviral naive \& Time since } \\
\text { HIV diagnosis at M0 }\end{array}$} \\
\hline $\begin{array}{l}\text { Antiretroviral naive } \& \text { time since } \\
\text { diagnosis }<8 \text { years at M0 }\end{array}$ & $377(35.7)$ & $0.8[0.5 ; 1.2]$ & 0.350 & $1.0[0.6 ; 1.7]$ & 0.963 \\
\hline $\begin{array}{l}\text { Antiretroviral naive } \& \text { time since } \\
\text { diagnosis } \geq 8 \text { years at } \mathrm{M} 0\end{array}$ & $83(7.8)$ & $2.9[1.7 ; 5.0]$ & 0.000 & $2.8[1.4 ; 5.4]$ & 0.003 \\
\hline Not antiretroviral naive at M0 & $595(56.3)$ & 1 & & 1 & \\
\hline \multicolumn{6}{|l|}{ Coinfection with HCV at M0 } \\
\hline No & 779 (73.7) & 1 & & & \\
\hline Yes & $231(21.8)$ & $1.8[1.2 ; 2.6]$ & 0.003 & & \\
\hline \multicolumn{6}{|l|}{ CD4+ cell count $/ \mathrm{mm}^{3}$ at $\mathrm{M0} \& \mathrm{M} 4$} \\
\hline $\begin{array}{l}\quad<200 \text { at } \mathrm{M} 0 \text { and } \geq 200 \text { at M4 (at M1 } \\
\text { if missing) }\end{array}$ & $235(22.2)$ & $1.2[0.7 ; 1.9]$ & 0.569 & $0.6[0.3 ; 1.2]$ & 0.191 \\
\hline $\begin{array}{l}<200 \text { at M0 and }<200 \text { at M4 (at M1 } \\
\text { if missing) }\end{array}$ & $114(10.8)$ & $3.1[1.9 ; 4.9]$ & 0.000 & $2.3[1.3 ; 4.1]$ & 0.006 \\
\hline \multicolumn{6}{|l|}{ Plasma HIV RNA at M0 (copies/mL) } \\
\hline$\leq 100,000$ & $736(69.6)$ & 1 & & 1 & \\
\hline$>100,000$ & $318(30.1)$ & $2.2[1.5 ; 3.2]$ & 0.000 & $1.7[1.0 ; 2.9]$ & 0.032 \\
\hline \multicolumn{6}{|l|}{ Haemoglobin $^{\S}(\mathrm{g} / \mathrm{dL})$} \\
\hline$\geq 13(12)$ for men(women) & $881(83.3)$ & 1 & & 1 & \\
\hline < 13(12) for men(women) (anemia) & $176(16.6)$ & $2.7[1.8 ; 4.0]$ & 0.000 & $2.4[1.5 ; 3.7]$ & 0.000 \\
\hline
\end{tabular}




\begin{tabular}{|c|c|c|c|c|c|}
\hline $\begin{array}{l}\text { Indicator of liver fibrosis FIB-4 }^{\S} \\
\quad \leq 3.25 \\
>3.25 \text { (advanced fibrosis) }\end{array}$ & $\begin{array}{c}998 \text { (94.4) } \\
59(5.6)\end{array}$ & $\begin{array}{c}1 \\
3.1[2.0 ; 4.9]\end{array}$ & 0.000 & $\begin{array}{c}1 \\
2.5[1.5 ; 4.3]\end{array}$ & 0.000 \\
\hline \multicolumn{6}{|l|}{ HIV transmission category } \\
\hline IDU & $181(17.1)$ & $1.2[0.8 ; 1.8]$ & 0.437 & & \\
\hline Sex between men & 438 (41.4) & $0.5[0.3 ; 0.8]$ & 0.003 & & \\
\hline Other & 438 (41.4) & 1 & & & \\
\hline \multicolumn{6}{|l|}{ High school certificate at M0 } \\
\hline No & $686(64.9)$ & 1 & & & \\
\hline Yes & $352(33.1)$ & $0.7[0.5 ; 1.1]$ & 0.162 & & \\
\hline \multicolumn{6}{|l|}{ Being employed at M0 } \\
\hline No & $434(41.1)$ & 1 & & & \\
\hline Yes & $575(54.4)$ & $0.7[0.4 ; 0.9]$ & 0.043 & & \\
\hline \multicolumn{6}{|l|}{ Stable housing at M0 } \\
\hline No & $217(20.5)$ & 1 & & & \\
\hline Yes & $840(79.5)$ & $0.7[0.4 ; 1.0]$ & 0.066 & & \\
\hline \multicolumn{6}{|l|}{ Comfortable housing at M0 } \\
\hline No & 147 (13.9) & 1 & & & \\
\hline Yes & $888(84.0)$ & $0.6[0.4 ; 1.0]$ & 0.056 & & \\
\hline $\begin{array}{l}\text { Social vulnerability indicator at M0 } \\
\text { (from MCA) }\end{array}$ & $\begin{array}{c}-0.35 \\
{[-0.47 ; 0.51]}\end{array}$ & $1.3[1.1 ; 1.6]$ & 0.003 & $1.2[1.0 ; 1.5]$ & 0.033 \\
\hline \multicolumn{6}{|l|}{ Depressive symptoms ${ }^{\S}$} \\
\hline $\begin{array}{l}\text { No }(\text { CES-D } \leq 17(23) \text { for } \\
\text { men(women }))\end{array}$ & $695(65.7)$ & 1 & & & \\
\hline $\begin{array}{l}\text { Yes (CES-D > 17(23) for } \\
\text { men(women)) }\end{array}$ & $356(33.7)$ & $1.9[1.3 ; 2.7]$ & 0.001 & & \\
\hline \multicolumn{6}{|l|}{ Alcohol consumption $^{\S}$ (AU/day) } \\
\hline No consumption & $212(20.1)$ & 1 & & 1 & \\
\hline Low $(\leq 1)$ & $614(58.1)$ & $0.4[0.2 ; 0.6]$ & 0.000 & $0.6[0.4 ; 1.0]$ & 0.044 \\
\hline $\begin{array}{l}\text { Moderate }(>1 \text { and } \leq 4(3) \text { for } \\
\text { men(women)) }\end{array}$ & $188(17.8)$ & $0.6[0.4 ; 1.0]$ & 0.070 & $0.8[0.4 ; 1.6]$ & 0.628 \\
\hline Elevated (> 4(3) for men(women)) & $43(4.1)$ & $0.5[0.5 ; 1.2]$ & 0.118 & $0.7[0.2 ; 1.8]$ & 0.459 \\
\hline
\end{tabular}


$\mathrm{IQR}=$ interquartile range; $(\mathrm{A}) \mathrm{HR}=($ adjusted $)$ hazard ratio; $\mathrm{CI}=$ confidence interval; $\mathrm{CES}-\mathrm{D}=\mathrm{Center}$ for Epidemiologic Studies Depression scale; HCV = hepatitis C virus; $\mathrm{AU}=$ alcohol unit; IDU = injection drug use $;$ CDC $=$ Centers for Disease Control and Prevention

$\S$ Time-varying variable

$\S \S$ The frequencies are reported at M0 for fixed variables, and at the first available visit between M4-M144 for time-varying variables 
Figure 1. Cumulative hazard function for death according to the dropout time (before M20, between M20 and M60, after M60), the ANRS CO8 APROCO-COPILOTE cohort (M4M144)

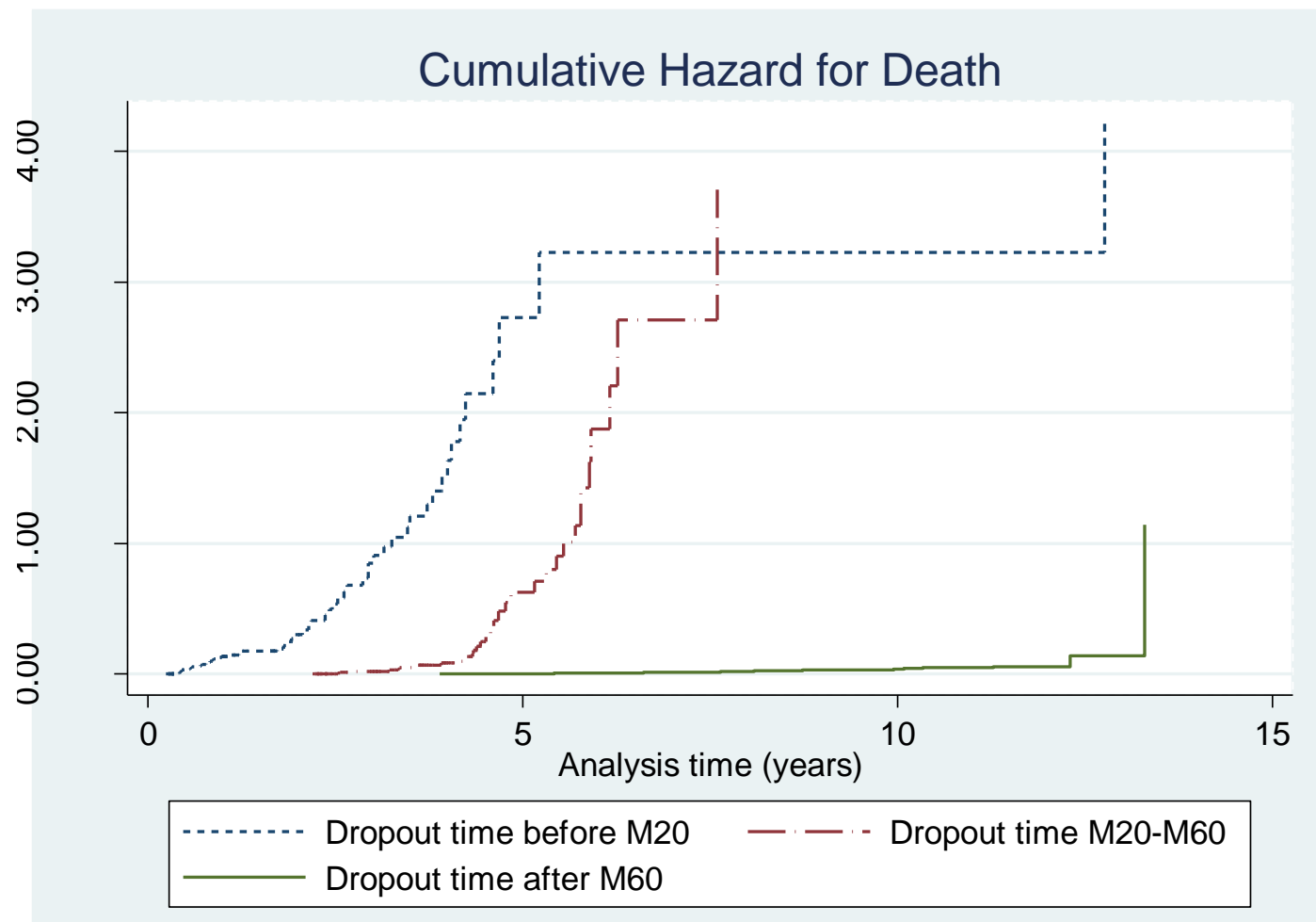




\section{Appendix}

The shared-frailty Cox proportional hazards (PH) model

The conditional hazard function of the model, given the unobserved frailty variable $w_{i}$ for the $i$ th cluster and the covariate vector $\underline{x}_{i j}$ is defined by:

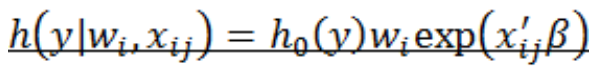

where $\underline{\beta}$ is the vector of unknown model coefficients, $\underline{h}_{0}(\cdot)$ is the baseline hazard ratio common to all subjects, $\underline{x}_{i j}$ is the covariate vector for the $j$ th subject in the $i$ th cluster, and the frailty variables $\underline{w}_{i}$ are assumed to be independently Gamma distributed with a mean of 1 and unknown variance $\underline{\theta}_{i}$. The interpretation of regression coefficients $\underline{\beta}$ remains the same as in the standard Cox $\mathrm{PH}$ model, but is conditionally made on the frailty variables $\underline{w_{i}}$ which explicitly account for the extra variance associated with unmeasured risk factors.

A likelihood ratio (LR) test for the variance of the frailty variable (LR test for $\underline{\theta_{i}=0}$ ) was used to compare the shared-frailty Cox PH specification versus the standard Cox PH specification. 